\title{
A NOTE ON THE SUBREGIONAL EMPLOYMENT IMPACT OF URBAN REVITALIZATION
}

\author{
Reza Banai-Kashani*
}

\section{Introduction}

In the 1970's and 1980's public inducements and joint public-private initiatives (Stout and Vitt, 1982) spurred the process of revitalization in North American cities in a pace unprecedented since the urban renewal decades of the 1950's and 1960's. ${ }^{1}$ The increased real estate development activity and infrastructure reinvestments in the downtowns stimulated an interest in accounts of benefits and costs of revitalization and, particularly in the impact of downtown revitalization on the economy of the city. Consequently, a number of studies has emerged (e.g., Degiovanni, 1984; Ircha, 1984; Laventhol, 1984) that commonly trace the employment and expenditure impacts of downtown revitalization on the economy of the city. A striking limitation of such studies, however, is their lack of attention to the spatial interaction phenomenon: The impact of the economy of the revitalizing city on its surrounding and depending economies.

Estimates of permanent vs. non-permanent employment ordinarily are reported in studies of the economic impact of downtown revitalization. However, still a further distinction of employment as "basic" vs. "non-basic" types is of particular interest since, at least in economic-base theory, the former is the source of additional (induced) employment change. Thus, the argument in this paper brings into the calculus of the economic impact of city revitalization the distinction of basic vs. non-basic employment and its associated concept of the multiplier impacts. But more important, cognizant of previous empirical studies attesting to the existence of the multiplier-decay hypothesis (e.g., Erickson, 1977; Richardson and Gordon, 1978; Richardson, 1985), this study accounts for the impact of the economy of the revitalizing city on its surround-

\footnotetext{
*Assistant Professor of City and Regional Planning, Deparment of Geography and Planning, Memphis State University. The author gratefully acknowledges the opportunity provided by the editor of this journal to incorporate the constructive comments of the anonymous referees in this version of the paper. This paper extends a recent (1985) study of the Economic Impact of Downtown Revitalization in Memphis, Tennessee, under a grant from the U.S. Economic Development Administration, with the author as principal investigator. I wish to acknowledge my colleague, Professor T. Mealor who commented on an earlier version of this paper. My student, Mr. J. Wu assisted with data collection.
}

ing and depending subregional economies.

It turns out that the employment multiplier estimates are approximated by a distance-decay function with a high degree of statistical significance, even when the number of subregions ( as observations) is small: The employment impacts on the surrounding counties (subregions) decay with the distance from the core (downtown) of the revitalizing city. This finding is significant in the face of previous studies that, in deference to a small number of zones, were statistically restrained to confirm the plausibility of the multiplier-decay hypothesis. Furthermore, the estimates fall within the approximate range of the employment and expenditure multiplier estimates obtained by other studies (in particular, Erickson, 1977; Richardson and Gordon, 1978). The use of spatial multipliers thus is suggested, extending the scope of existing studies that characteristically have negated the interaction of spatial economies, particularly in accounting for the greater territorial or "subregional" incidence of the economic impact of urban revitalization.

\section{Procedure and Data}

Among studies that develop a spatial context in quantifying their economic impacts two are uniquely relevant for the purposes of this paper. One is a study by Erickson (1977) that involves simulation of spatial (subregional) expenditure multipliers. The study by Erickson involves a small number of zones ( 10 Wisconsin communities, one of which is Madison); the other study by Richardson and Gordon (1978) derives and statistically estimates spatial employment multipliers. In the latter study, a larger number of zones (81 in Los Angeles and Orange counties, CA) was analyzed with a negative exponential function resulting in the best fit (relative to linear or $\log$-linear forms) of the multiplier-decay function $\left(r^{2}=\right.$ 0.794 ). When 10 (Wisconsin) communities from the study by Erickson were used as observations, however, the linear, log-linear and negative exponential functional forms accounted for only 59.9, 53.5 and 49.9 percent, respectively, of the variation in the multiplier values due to the distance from the basic expenditure zone, (Richardson and Gordon, 1978).

In this paper an alternative version of the GarinLowry model is used (Garin, 1966; Oppenheim, 1980; Richardson, 1985), and made operational principally with 
the Census Urban Transportation Planning System (UTPS) data as its inputs, in the absence of direct survey information. ${ }^{2}$ The resulting multiplier estimates, as well as variable measure and form of the multiplier-distancedecay function in this paper, can be compared, however, with those obtained in previous studies. the form: ${ }^{3}$

The subregional employment multiplier model has

$$
T=[I-(C B W A)]^{-1} E(b)
$$

where

$\mathrm{T}=$ vector of total employment by zone (Dimension: $\mathrm{n} \times 1$ )

$\mathrm{I}=$ identity matrix $(\mathrm{n} \times \mathrm{n})$

C = journey-to-services probability matrix $(n \times n)$

$B=$ diagonal matrix of service jobs equivalents by zone $(\mathrm{n} \times \mathrm{n})$

$\mathrm{W}=$ diagonal matrix of reciprocal of work-force ratios by zone ( $\mathrm{n} \times \mathbf{n})$

$A=$ journey-to-work (basic jobs) probability matrix $(\mathrm{n} \times \mathrm{n})$

$E(b)=$ vector of basic employment by zone ( $\mathrm{n} \times 1)$

The essential spatial interaction phenomenon is captured by the journey-to-services and the journey-towork (i.e., basic jobs) matrices in which the zone origins and destinations of the commuters are specified (discussed further in the context of the data source which follows). The model can be used flexibly for determining the effect of changes involving, for example, the commuting pattern (changing $\mathrm{A}$ and $\mathrm{C}$ ), the zonal employment participation pattern (W), the zonal number of service workers per unit of residential population (B), as well as the impact of the change in the number of basic jobs within a zone, $\mathrm{E}(\mathrm{b})$, on total employment in each zone (T). ${ }^{4}$

This model is used for estimating both employment and employment change, with one city and nine counties as zones (or subregions) of the model. The impact of the addition in "basic" employment due to the revitalization in one zone (the city) on the remaining zones (surrounding counties) is stimulated and the resulting employment changes then are fitted to derive estimates of (subregional) employment multipliers. ${ }^{5}$ The revitalized zone is the City of Memphis, Tennessee, which has experienced the rejuvenation of its downtown since 1977, adding an estimated 5,790 permanent jobs associated with public and private investment of approximately 428 million dollars from 1977 through 1984 (REDC, 1985). A two-way classification of the employment impact of city revitalization is given in Table 1.

The impact of the change resulting from a 1,000-increase in basic employment due to downtown revitalization was simulated to determine the value of the employment multiplier. The impact of the estimated total increase in basic employment can be determined, however, from the resulting multiplier value, given the linear form of the spatial employment multiplier model.

The principal source of data for this simulation was the urban transportation planning system (Census UTPS, 1980). The UTPS provided commuting linkage data, as well as information on the type of employment ${ }^{6}$ of the commuters, both vital for the purposes of spatial economic impact analysis. Using location quotients (LQ), employment was further subdivided into "basic" (LQ $>1)$ and "non-basic" (LQ $\leq 1)$ types. The 10 zones combined (one city and nine counties) to constitute the "parent" economy in the calculation of the location quotients. After determining the type of employment of the commuters, by basic vs. non-basic (services), the journey-to-basic and journey-toservices matrices A and C, respectively, were constructed. Dividing each element in every column by its column totals transformed matrices $\mathrm{A}$ and $\mathrm{C}$ into probability matrices (ensuring that each column totaled 100 percent). ${ }^{7}$ In effect, commuters are allocated, via matrices $\mathbf{A}$ and $\mathbf{C}$, to each employment zone $\mathrm{j}$ from the residential zones $\mathrm{i}$. The Census of Population (AR, MS, TN, 1980) provided zonal (residential) population figures as data for construction of

Table 1

Employment Impact of City Revitalization: Memphis TN: 1977-1984

\begin{tabular}{lcc}
\hline \hline Employment & Permanent & Non-Permanent \\
\hline Basic & 4,860 & - \\
Non-Basic & 930 & 7,363 \\
Total & 5,790 & 7,363 \\
\hline \hline
\end{tabular}

${ }^{1}$ Retail, Services and FIRE employments classified by location quotient value of $>1$ as "basic" employment; ${ }^{2}$ Construction employment classified by location quotient value of $\leq 1$ as "non-basic" employment.

Source: Based on impact data from REDC (1985). ${ }^{5}$ 
Table 2

Observed vs. Simulated Total Employment, by Zone, Memphis, Tennessee, Area, 1980.

\begin{tabular}{|c|c|c|c|c|c|}
\hline & $\begin{array}{l}\text { Subregion } \\
\text { (zone) }\end{array}$ & $\begin{array}{c}\text { Observed } \\
\text { Employment }\end{array}$ & $\begin{array}{c}\text { Estimated } \\
\text { Employment }\end{array}$ & Error & Distance \\
\hline & & (Number) & (Number) & (Percent) & (Miles) \\
\hline City: & Memphis (TN) & 553,993 & 557,015 & 0.55 & - \\
\hline \multirow[t]{10}{*}{ County: } & Crittenden (AR) & 11,856 & 14,143 & 19.23 & 13.3 \\
\hline & Shelby (TN) & 42,099 & 46,710 & 10.95 & 14.7 \\
\hline & Desoto (MS) & 13,572 & 13,457 & -0.85 & 20.0 \\
\hline & Tipton (TN) & 7,120 & 5,113 & -28.19 & 34.7 \\
\hline & Poinsett (AR) & 293 & 293 & 0.00 & 34.7 \\
\hline & Cross (AR) & 181 & 200 & 10.50 & 40.0 \\
\hline & Marshall (MS) & 519 & 523 & 0.77 & 40.0 \\
\hline & St. Francis (AR) & 312 & 279 & -10.58 & 41.3 \\
\hline & Mississippi (AR) & 155 & 176 & 13.55 & 44.0 \\
\hline & Total & 630,100 & 637,909 & 1.24 & - \\
\hline
\end{tabular}

diagonal matrix $B$, representing the number of service jobs per unit of residential population in each zone, and for construction of diagonal matrix $\mathrm{W}$, the inverse of the employment participation rate for each zone. The employment data for matrices (B and W), however, were obtained entirely from the UTPS $(1980){ }^{8}$ The model simulated total employment vs. observed 1980 total employment is given in Table 2.

The observed and simulated total employment figures are very close, particularly for total employment in the city ( 0.55 percent error) and total employment in all zones (1.24 percent error). The errors in the estimates of the re- maining zonal totals can be examined further in the face of data imperfections and limitations of the location quotient technique. Thus, the spatial multiplier model specified earlier was used to simulate the impact of a change in "basic" employment in one zone (City of Memphis downtown revitalization) on the remaining zones of the model economy (nine counties). The results of this simulation of a 1,000-basic employment addition in the revitalizing City of Memphis, are shown in the first column of Table 3 as new total zonal employment estimates. The absolute and relative changes in zonal employment are shown in the second and third columns of Table 3, respectively.

Table 3

Subregional Impact of a 1,000-Increase in

Basic Employment in the City of Memphis

\begin{tabular}{llrrcc}
\hline \hline Subregion & $\begin{array}{c}\text { Employment } \\
\text { New Totals }\end{array}$ & $\begin{array}{c}\text { Employment } \\
\text { Change }\end{array}$ & $\begin{array}{c}\text { Employment } \\
\text { Change }\end{array}$ & Distance \\
\hline \multirow{3}{*}{ City: } & Memphis (TN) & Number & Number & Percent & Miles \\
County: & Crittenden (AR) & 14,168 & 1,262 & 0.23 & - \\
& Shelby (TN) & 46,747 & 25 & 0.18 & 13.3 \\
& Desoto (MS) & 13,465 & 37 & 0.08 & 14.7 \\
& Tipton (TN) & 5,115 & 2 & 0.06 & 20.0 \\
Poinsett (AR) & 293 & 0 & 0.04 & 34.7 \\
Cross (AR) & 200 & 0 & 0.00 & 34.7 \\
Marshall (MS) & 523 & 0 & 0.00 & 40.0 \\
St. Francis (AR) & 280 & 1 & 0.36 & 40.0 \\
Mississippi (AR) & 177 & 1 & 0.57 & 44.0 \\
Total & 639,245 & 1,336 & 0.21 & - \\
\hline \hline
\end{tabular}


As in Table 2, the nine subregions (counties) are shown in order of increasing distance (in miles) from the location of the basic employment change (City of Memphis) in Table $3 .{ }^{10}$ Relatively large employment multipliers impacts ( 0.36 and 0.57$)$ are noted for two Arkansas counties (St. Francis and Mississippi), despite their distant locations from the City of Memphis (41.3 and 44 miles, respectively). Richardson and Gordon (1978) point out a similar "distortion" in data from the study by Erickson (1977) in which a community, despite its 35-mile distance from a defense procurement industry, registered a substantial expenditure multiplier impact. In general, when the impact of an economic or a demographic variable (such as population change) is small, there is reason to examine the size of the absolute change. That the measure of a variable change in relative terms may be large and misleading, particularly when the absolute change is quite small, is evidenced in the data presented here. The (simulated) employment change is much more reasonable in absolute measure, however, and a good statistical fit of the distancedecay function is obtained using this measure.

When absolute change ${ }^{11}$ in employment $(\mathrm{Tj})$ is regressed on distance (dij), and a log-linear functional relationship is assumed, a good fit (Figure 1) of the employment multiplier-decay function is obtained ( $t$-statistics in parentheses):

$\log \mathrm{Tj}=3.36-2.00 \log \mathrm{dij}$

(employment model, 10 zones)

$(12.73)(10.60)$

$$
\mathrm{p}<.01 \mathrm{p}<.025
$$

$$
r^{2}=0.934
$$

or after transformation:

$$
\mathrm{tj}=2290.86 \mathrm{dij}^{-2.00}
$$

This model explains more than 93 percent of the change in variation in the employment. The results can be compared to those of the log-linear models fitted for expenditure (based on output from the Erickson model) and employment by Richardson and Gordon (1978), respectively: ${ }^{11}$

$$
\begin{gathered}
\log \mathrm{Ej}=3.424-1.3034 \log \mathrm{dij} \\
\text { (expenditure model, } 10 \text { zones) } \\
r^{2}=0.535
\end{gathered}
$$

and

$$
\begin{aligned}
& \log \mathrm{Ej}=2.54-1.667 \mathrm{log} \mathrm{dij} \\
& \text { (employment model, } 81 \text { zones) } \\
& \quad \mathrm{r}^{2}=0.766
\end{aligned}
$$

The information in Table 3 indicates that a 1,000 basic employment change in the City of Memphis resulted in a simulated induced employment of 1,262 , and a simulated total employment of 2,262. The statistically derived (2) estimate (the coefficient of the log-linear model above) gives 2,290.86. Thus, the local employment multiplier falls within a range of 2.262 (simulation model) to 2.290 (statistical model) for the City of Memphis, compared to

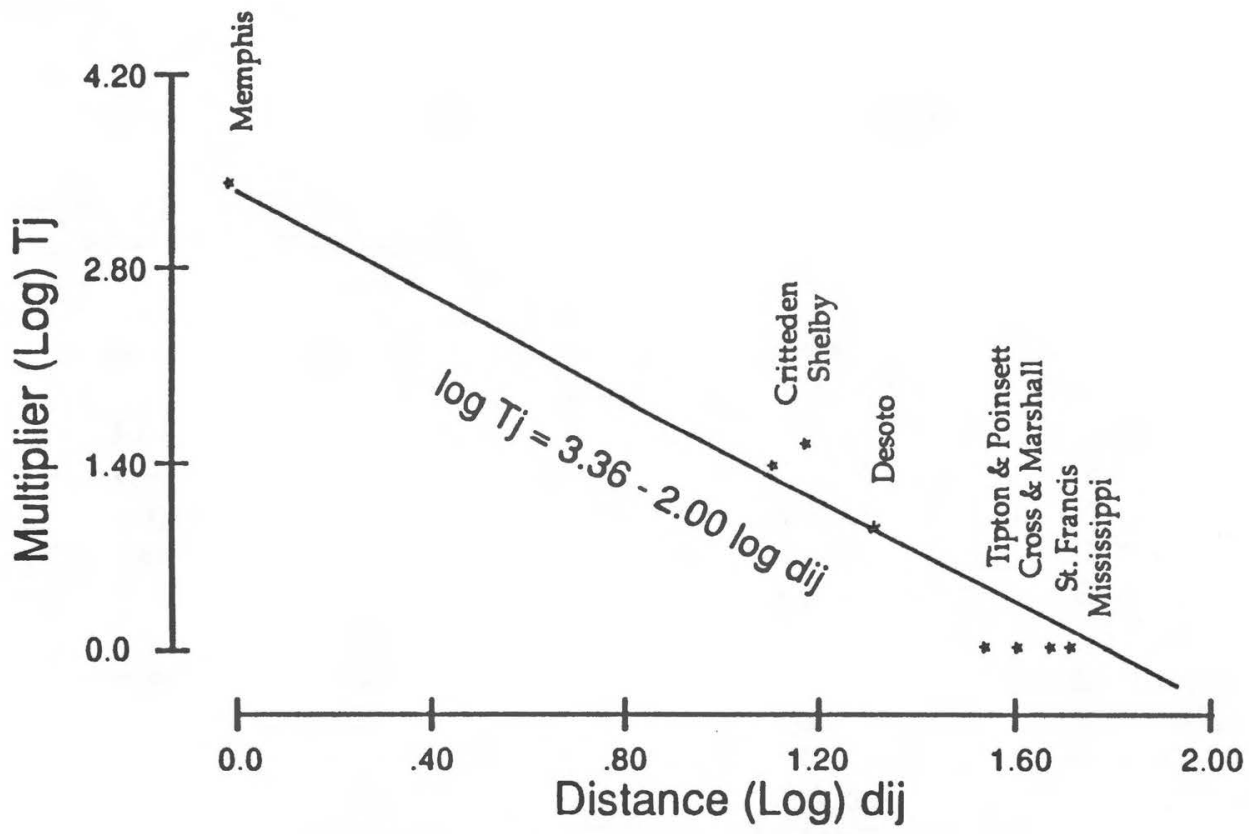

Figure 1. Decay of Employment Multiplier with Distance 
1.845 for the City of Long Beach, CA (Richardson and Gordon, 1978). ${ }^{12}$

Furthermore, the value of the distance decay parameter, the coefficient of dij (or alternatively, its exponent in the transformed version of the employment-distance-decay function), is -2.00 in the study area. In a gravity formulation, the distance decay parameter provides a measure of "responsiveness of interaction to spatial separation" (Haynes and Fotheringham, 1984). The larger the value of the coefficient, the smaller is the volume of commuting, all other things being equal. The empirically derived estimate of this coefficient for the study area reported here $(-2.00)$ is higher than the value derived by Richardson and Gordon (1978) for the Los Angeles and Orange County, California zones (-1.667), where a greater dispersion of employment was evident. The geography of the employment distribution/concentration; the level of income required to offset the cost of commuting (to work); and the distance perceptions of the people are among the factors affecting the measure of the responsiveness of interaction to spatial separation.

\section{Conclusions}

The regression model, however simple, provides an empirical observation of the spatial economic impact process that is grounded in theory. The classical regional economic theorists, Myrdal and Hirshman, pointed out the "spread-effects" or "trickle-down" effects of a capitalist process of economic growth on spatially distributed population groups (Freidmann and Weaver, 1979, pp. 114-115). The use of commuting data in the spatial multiplier model, endogenously affecting the values of the employment change variable $(\mathrm{Tj})$ in the regression model, provides a behavioral measure of the "labor mobility", that was conceived as a condition necessary for the notions of spreadeffects and trickle-down effects of economic growth to hold. Furthermore, the estimated regression equation is analogous to the working of a gravity model in the realm of spatial multipliers (Richardson and Gordon, 1978), describing the incidence of economic impact as decreasing with increasing distance. Further extension of this model fruitfully could include a temporal dimension, to trace the dynamics in the incidence of spatial economic impacts, once time series data are made available.

Even when the number of subregions (zones) is small, data are limited and/or direct survey information on work and shopping commuting patterns are unavailable, the simulation reported here renders the multiplier-decay hypothesis plausible. Furthermore, a variable measuring absolute rather than relative employment change in the multiplier-distance-decay function exhibits greater ac- countability when the economic impact is small. Juxtaposed with the case in which the number of subregions is large, as previously noted, this additional empirical evidence suggests a rationale for enlargning the scope of economic impact studies, in particular, to account for the benefits and costs of changing the economic base of a city. Thus the aggregate (non-spatial) multiplier commonly reported for a city undergoing revitalization of its downtown may misrepresent the more precise, spatial-economic consequences of the revitalization process.

Finally, further use of the proposed approach for planning and simulation model testing could involve the use of direct survey data. Comparison of the simulated model output with a direct, albeit costly and time-consuming, survey of, for example, the impact of opening or closing plants in one zone on the remaining zones could shed additional light on the accuracy of simulation model predictions of observed impacts.

\section{Notes}

'In particular, the U.S. Department of Housing and Urban Development, with its CDBG and UDAG programs, and funding from the Economic Development Administration and the Department of Transportation were instrumental in the city rebuilding process during this period (Stout and Vitt, 1982; Witherspoon, 1982; HUD, 1984). Comparable public inducements are found in the process of the revitalization of Canadian cities (Ircha, 1984).

${ }^{2}$ The model used by Richardson and Gordon (1978) has the form:

$$
E=[I-(A B C D)+F G)]^{-1} E(b) .
$$

See Richardson and Gordon for the definition of the model variables.

${ }^{3}$ See Oppenheim (1980) for a further discussion and a (small, 3-zone) numerical example of the model used in this paper.

${ }^{4} \mathrm{~A}$ computer program in BASIC, for the mainframe computer that calculates total employment by zone $(T)$ for the specified values of the various matrices in the model is available from the author upon request. A variety of economic impact scenarios can be simulated by changing the data for the model variables (on the right-hand-side), and thereby tracing the associated change in the total employment of each zone.

${ }^{5}$ After examining the sectoral distribution of employment in 32 large cities, Richardson (1978) notes that basic industries are found outside manufacturing. Thus, Richardson [p.254] argues that nonlocal business services, FIRE, tourism, and govemment, are as basic as manufacturing, if "basic" industries are defined as activities serving markets beyond metropolitan area boundaries.

'Eleven categories of employment were used, including: Agriculture, Forestry and Fisheries; Mining; Construction; Manufacturing; Transportation, Communication and Public Utilities; Wholesale and Retail Trade; Finance, Insurance and Real Estate (FIRE); Services; Public Administration; and Armed Forces.

${ }^{7}$ Data used in the construction of matrices for the model variables are available from the author upon request.

${ }^{8}$ A check on employment data from Census UTPS and 
Census of Population revealed compatibility of the two census sources.

'Further research could examine the sensitivity of the simulation model output by experimenting with the spatial (base area) delineation and the level of industrial (sectoral) disaggregation (or aggregation) by using the index of locational specialization (LQ), or its alternatives, notwithstanding certain limitations of the LQ technique of sectoral bifurcation or base area delineation (e.g., Isserman, 1980; Richardson, 1978a;1985).

10Distances (in miles) were measured along the highway and or the next level primary road connecting the CBD of the city with the centroid of each county.

"The employment variable in the Richardson and Gordon study measured relative, rather than absolute, change due to basic employment increase in one zone. However, it turns out, at least in the case of small number of zones, that the fit of the model is adversely affected when a relative measure of employment change is used.

${ }^{12}$ The author also has experimented with a negative exponential form that resulted in the fitted model:

$$
\begin{gathered}
\ln \mathrm{Tj}=7.73-2.00 \ln \mathrm{dij} \\
(13.05)(10.87) \\
r^{2}=.937
\end{gathered}
$$

or after transformation:

$$
t j=2275.6 e^{-200 d i j}
$$

giving a slightly better fit than the log-linear model above.

\section{References}

Census of Population, Characteristics of the Population, TN-ARMS, 1980.

Census Urban Transportation Planning System Package (UTPS), Memphis, TN-AR-MS SMSA, 1980.

DeGiovanni, F.F. "An Examination of Selected Consequences of Revitalization in Six U.S. Cities." Urban Studies. 21 (1984). 245-59

Erickson, R.A. "Subregional Impact Multipliers: Income Spread Effects from a Major Defense Installation." Economic Geog. raphy. 53 (1977). 283-94.

Friedmann, J. and C. Weaver Territory and Function-The Evolu tion of Regional Planning CA: University of California
Press, 1979.

Garin, R.A. "A Matrix Formulation of the Lowry Model for Intrametropolitan Activity Allocation." Joumal American Institute of Planners. 32 (1966). 361-4.

Haynes, K.E. and A.S. Fotheringham Gravity and Spatial Interaction Models. Beverly Hills: Sage, 1984.

Ircha, M. C., "Downtown Revitalization: Are the Benefits Worth the Costs?" Dept. of Civil Engineering, Federicton, N.B.: University of New Brunswick Mimeo., 1984.

Isserman, A.M. "Estimating Export Activity in a Regional Economy: A Theoretical and Empirical Analysis of Alternative Methods." Intemational Regional Science Review. 5 (1980). 155-184.

Laventhol, et al. "The Economic Impact of Downtown Kansas City, Missouri." Kansas City, MO, Mimeo., 1984.

Lowry, I.S. A Model of Metropolis. Santa Monica: Rand Corporation, Research Memorandum RM-4035-RC, 1964.

Oppenheim, N. Applied Models in Urban and Regional Analysis, NJ: Prentice-Hall, 1980.

Regional Economic Development Center (REDC) "A Study of the Economic Impact of Downtown Revitalization on Memphis and Shelby County." Memphis, TN: Memphis State University, Monograph, 1985.

Richardson, H.W. "Basic Economic Activites in Metropolis." In C.L. Leven(ed.) The Mature Metropolis. MA: Lexington Books, 1978.

"The State of Regional Economics: A Survey Article." International Regional Science Review. 3,1 (1978a). 148.

- "Input-Output and Economic Base Multiplier: Looing Forward and Backward." Joumal of Regional Science. 25,4 (1985). 608-661.

and P. Gordon "A Note on Spatial Multipliers." Economic Geography. 54 (1978). 309-13.

Stout, G.E. and J.E. Vitt "Public Incentives and Financing Techniques for Codevelopment." Washington, D.C.: The Urban Land Institute, 1982.

U.S. Department of Housing and Urban Development, HUD, Working Partners. Washington, D.C.: Office of Community Planning and Development, 1984.

Witherspoon, R. "Codevelopment: City Rebuilding by Business and Government." Washington, D.C.: The Urban Land Institute, 1982 